\title{
Healthcare professionals' perspective on delivering personalised and holistic care: using the Theoretical Domains Framework
}

Eunice Wong ${ }^{1,2^{*}}$, Felix Mavondo ${ }^{3}$, Lidia Horvat ${ }^{4}$, Louise McKinlay ${ }^{4}$ and Jane Fisher ${ }^{2}$

\begin{abstract}
Background: Interventions to improve personalised and holistic care delivery by healthcare professionals are more likely to be effective if they target the factors influencing specific behaviours. This study reports on the development and testing of a questionnaire to identify perspectives of healthcare professionals' personalised and holistic care behaviours based on the Theoretical Domains Framework.

Methods: The study was conducted in public health services in Victoria, Australia. The questionnaire was developed and pilot-tested with behaviour change researchers and healthcare professionals. Doctors, nurses and midwives were recruited via notices and email invitations from Safer Care Victoria's website and mailing lists of healthcare professionals and invited to completed the questionnaire online (hosted on Qualtrics). Health services administrators and allied health professionals were excluded from the study. Confirmatory factor analysis was undertaken to generate the model of best fit and group differences were tested using univariate tests.
\end{abstract}

Results: One hundred and four healthcare professionals from public health services in Victoria, Australia, completed the 39-item questionnaire focusing on specific personalised and holistic care behaviours. The final model consisted of 13 factors and 39 items, and CFA produced an acceptable fit, as well as adequate levels of discriminant validity and internal consistency ( $a=0.60$ to 0.84 ). Seven domains, "social influence", "motivation \& goals", "environmental context and resources', "skills", 'beliefs about consequences", "behaviour regulation" and "nature of behaviour" were identified. Significant differences in the factors influencing these behaviours were found in groups with different years of experience and role seniority. These findings suggest that future interventions need to be targeted to specific groups.

Conclusion: This study identified the specific behaviours and the factors associated with performance of personalised and holistic care among healthcare professionals. The findings suggest several interventions and policy functions may be taken to improve personalised and holistic care.

Keywords: Person-centred care, Theoretical Domains Framework, Behaviour change

\section{Background}

Increasingly, policymakers, researchers and practitioners recognise the need to shift from the paternalistic and service-centric model of 'physician knows best' to a more

\footnotetext{
*Correspondence: eunice.wong@monash.edu

${ }^{1}$ Monash Sustainable Development Institute, BehaviourWorks Australia,

Monash University, Melbourne, Australia

Full list of author information is available at the end of the article
}

collaborative and consultative approach with patients about their needs and experiences as users of health services. The focus is now on partnering with patients and their families in designing care, information and care pathways that fit the patient's needs. This patient-centred care approach is associated with increased adherence and clinical benefits $[1,2]$ and reduced unnecessary health service visits $[3,4]$. 
The Australian Commission on Safety and Quality in Health Care in Australia introduced the National Safety and Quality Health Service (NSQHS) standards (second edition) [5] in 2017 with a focus on partnering with patients. Following this, the state health authorities developed additional frameworks and guidelines to support health services to meet these standards. In the state of Victoria, Safer Care Victoria, in the Department of Health (DHS), developed a new framework 'Partnering in Healthcare', focusing on five key areas: 'personalised and holistic care', 'effective communication', 'equity and inclusion' 'shared decision-making' and 'working together' as a guide for health services in their work to improve patient experience and outcomes [6]. Safer Care Victoria worked with the public health services and 'personalised and holistic care' was one of the areas identified for implementation.

Despite all these initiatives, there is little evidence that patient experiences of care have improved significantly. A recent study in Victoria found that despite efforts by health services to improve the care delivered, patient experience scores have remained at 93\%, below the target of $95 \%$. It was found that more focus on dignity and respect; and emotional support could improve overall patient experience [7].

Interventions have typically been developed without a clear articulation of the theory of change [8, 9], often addressing the challenges with training or education, rather than using theory to understand the barriers and levers for behaviour change [10, 11].

To identify healthcare professionals' behaviours associated with personalised and holistic care. The 'Partnering in Healthcare' framework [12] first defines it as understanding the whole person (or family); physical, cultural, social context, and differences in person's health, wellbeing and safety. The elements include putting people and families at the centre of care, providing emotional support and empathy, involving family and friends and showing compassion and respect. A recent qualitative study identified specific, measurable actions associated with these concepts, particularly behaviours that i) build relationships such as taking time with patients, active listening, expresses caring and empathy; ii) personalised care practices such as the inclusion of family, knowing the patient, eliciting and respecting patients' values [13]. The second step is understanding the factors that influence the performance of behaviours associated with personalised and holistic care.

Theoretical models and frameworks for behaviour change of healthcare professionals have been proposed for clinical practices for the management of different conditions [10, 14-16]. Many of which identify individual factors (knowledge, skills, self-efficacy); social factors (social support, group norms); and environmental factors (resources, organisational climate). The Theoretical Domains Framework (TDF) $[17,18]$ proposes an integrated theoretical framework where 128 commonly related constructs are grouped into 12 domains to aid in identifying influences on the behaviour. Subsequently, the TDF authors further expanded on their work with the behaviour change wheel (BCW) [19] to provide a guide to identifying interventions to target the factors influencing the behaviours.

Research using TDF to understand and change healthcare professionals' behaviours has mostly been qualitative $[14,17,20]$. This has provided a rich detailed understanding of the factors for change, but these studies cannot be generalised. There are a small number of studies where TDF has been used to develop questionnaires with selected domains and constructs that were assessed as relevant to the respective contexts examining healthcare professionals' behaviours towards clinical practice guidelines [21], patient safety [22] and smoking [23]. From the above mentioned TDF questionnaire studies, it is observed that not all domains and constructs are comprehensively covered, prioritisation was conducted based on the context of the target behaviour, admittedly respondent fatigue may be a key consideration. To the best of our knowledge, the application of TDF to the development of a questionnaire to understand healthcare professionals' personalised and holistic care behaviours does not exist in the literature. The use of a questionnaire based on the TDF can identify key factors for behaviour change that can be applied to all health services. This allows reaching out to a larger sample and providing robust findings for policy interventions.

The aim was to develop and test a questionnaire using the TDF to understand healthcare professionals' perspectives on performing personalised and holistic care behaviours.

\section{Methods \\ Measure \\ Development of the views and experiences of personalised and holistic care questionnaire}

Consultation with Safer Care Victoria to identify target behaviours Consultation sessions with Safer Care Victoria's Partnering in Healthcare framework team were conducted to identify target behaviours. As personalised and holistic care is multifaceted, Safer Care Victoria's team highlighted that in practice, identifying and prioritising a single behaviour was inadequate and not representative. Other questionnaire studies guided by TDF addressed this challenge in the following ways i) use of broad non-behavioural statements such as 'follow/use 
current care guidelines' in studies [24-26], ii) restrict and prioritised only one behaviour as in the case of a study exploring clinicians performing patient safety behaviour [22] and iii) identify a set of behaviours described in respective care guidelines to be randomised for each item in studies [23, 27]. Based on the feedback on the context and inputs from the analysed qualitative data from Safer Care Victoria' framework development team six specific behaviours; 1) speak with patients about their anxieties/ fears with their health condition, 2) ask patients about the expectations of their care, 3) demonstrate respect and courtesy, 4) discuss patients' care goals with them, 5) review patients' medical information before meeting them and 6) introduce yourself to the patient and family, were identified to be randomised for item development to provide a more comprehensive representation of personalised and holistic care behaviours.

Items development The questionnaire items were developed based on the original 12 domain version of the TDF assessing the domains of behaviour change [26]. The findings from the regular update and adaptation of the framework to specific behaviours studied [24-26, 28], suggests that the original 12-domain version of the TDF instead of the updated 14-domain version might be more applicable for questionnaire design and only the domains relevant to the behaviours studied should be used.

In the development of the items, the authors reviewed and considered the relevance and application of each of the 12 domains of the TDF in clinical settings. Finally, two domains "Emotion" and "Memory, attention and decision processes" were excluded, based on the consideration that these domains may be more applicable to studying patient self-management behaviours but not as relevant to healthcare professionals' performance of personalised and holistic care behaviours. In addition, consideration was given to the length of the questionnaire with a view to minimise respondent fatigue. The authors debated and prioritised each construct through a process of elimination, including only keeping key constructs that were most relevant and observable and would not suffer from potential social desirability. This prioritisation was necessary as it was not feasible to ask questions for all theoretical constructs grouped under the ten domains.

The final questionnaire included 39 items assessing ten domains and their related key constructs that were relevant to healthcare professionals' personalised and holistic care behaviours (See Table 1). To assure the reliability of measures, a minimum of three items for each construct was developed. As this study is guided by the TDF, each item was developed to measure the corresponding theoretical construct, the authors with their extensive experience in clinical psychology, public health and questionnaire development conducted rounds of revisions to carefully construct the items to align to the theoretical definitions of the constructs.

Further considerations in the development of the items were to word them to include targets, actions, contexts and time, following Fisbein and Ajzen's approach [29] while retaining the theoretical content in each item. To reduce and address the social desirability bias

Table 1 TDF Domains and Description of Constructs

\begin{tabular}{|c|c|c|}
\hline TDF (10 domains) & Constructs (13) & Brief description of constructs \\
\hline Knowledge & 1.Knowledge & Know how to speak and interact with patients on their care \\
\hline Skills (Cognitive and Interpersonal) & 2.Skills & Interpersonal skills and consideration from patients' point of view \\
\hline \multirow[t]{2}{*}{ Behavioural regulation } & 3.Self-monitoring & Skills needed to monitor the behaviours \\
\hline & 4.Action planning & Skills needed to plan the behaviours \\
\hline Nature of behaviour & 5.Automaticity & Performing the behaviours without thought routines, habits \\
\hline Environmental context and resources & 6.Resources/materials & $\begin{array}{l}\text { The extent availability, physical or resource factors affect the delivery of patient- } \\
\text { centred care }\end{array}$ \\
\hline \multirow[t]{2}{*}{ Social influences } & 7.Social support & $\begin{array}{l}\text { Healthcare professionals (HCP) can count on their colleagues when there are } \\
\text { problems }\end{array}$ \\
\hline & 8.Subjective norm & HCP think that colleagues who matter to them approve of their behaviours \\
\hline Professional/social role and identity & 9.Professional role & HCPs view it as their professional role to perform these behaviours \\
\hline Beliefs about capabilities & 10.Self- efficacy & HCPs'self-belief in their ability to perform those behaviours \\
\hline Motivation and goals & 11.Priority & $\begin{array}{l}\text { HCPs' viewed it as important to perform these behaviours in comparison with other } \\
\text { tasks or behaviours }\end{array}$ \\
\hline \multirow[t]{2}{*}{ Beliefs about consequences } & 12.Reinforcement & HCPs' are recognised or not when they performed these behaviours \\
\hline & 13.Outcome expectations & $\begin{array}{l}\text { HCP think that there is a worthwhile outcome from their performance of these } \\
\text { behaviours }\end{array}$ \\
\hline
\end{tabular}


in self-report questionnaires [30], indirect questions rather than direct questions were included as much as possible [31]. The items were also adapted from i) previous studies $[25,26,32]$ that used the TDF in their questionnaires to understand healthcare professionals' behaviours or change behaviours in healthcare settings, ii) Safer Care Victoria's prioritised personalised and holistic care behaviours obtained from the development of the 'Partnering in Healthcare' framework [12]. This questionnaire was developed in collaboration with Safer Care Victoria and tested as part of their implementation work.

The demographic questions included in the questionnaire were age, gender, professional role, health service type (metropolitan, regional or rural), years of working experience and work status (full-time, part-time or casual).

Piloting of questionnaire Piloting was undertaken in two rounds. The first round was conducted with four behaviour change researchers with postgraduate training in behavioural science to determine whether items were worded clearly, had face validity for the constructs being measured and included target, action, context and time. They were also asked to pilot the functionality of the online survey platform (Qualtrics) hosting the questionnaire. Based on their feedback, amendments were made to the wordings of the items before further piloting.

The final round of piloting was undertaken with a varied group of seven healthcare professionals, nurses, midwives, and doctors with clinical and public health experience on the comprehension, face validity and the context of the items. Amendments to the final wordings of the items were made based on the feedback.

An online version of the questionnaire was used to measure the healthcare professionals' self-reported performance of personalised and holistic care behaviours. Each item was assessed on a 7-point Likert type scale ranging from $1=$ Never or Strongly Disagree to $7=$ Always or Strongly Agree. (See Additional file1 for questionnaire items).

\section{Participants \\ Inclusion and exclusion criteria}

Only participants who identified as doctors, nurses and midwives aged at least 18 years and working in public health services in the Australian state of Victoria were eligible to participate.

\section{Data collection procedure}

The online questionnaire was undertaken between 3 Aug and 8 Oct 2020. Safer Care Victoria disseminated the information of the study and hyperlink to the questionnaire (hosted on Qualtrics platform) on their website, Linkedin and Twitter platforms. Further dissemination was conducted by Safer Care Victoria via targeted emails to subscribers to their clinical networks e-newsletter and mailing lists of patient experience and partnering in healthcare coordinators in Victoria's public health services. The emails and posts invited interested participants to access the hyperlink to provide consent and participate in the questionnaire. No incentive was offered for completion, and participation was anonymous and entirely voluntary.

\section{Data analysis}

\section{Discriminant validity and internal consistency reliability}

The questionnaire was developed with a focus on ten domains with 13 specific constructs based on the Theoretical Domains Framework (TDF). Confirmatory factor analysis was used to identify the number of constructs in the questionnaire responses. Cronbach alpha was calculated to assess the internal consistency/reliability of the constructs. Convergent and discriminant validity were assessed through the calculation of the average variance extracted (AVE) and correlating the latent constructs.

\section{Group differences}

One-way ANOVA and t-tests were used to examine the perspectives of the professional group, role seniority, years of work experience, gender and type of health service category. The data were compiled and analysed using IBM SPSS V.26 and AMOS V.26.

\section{Ethics approval}

Ethics approval for this study was provided by the Monash University Human Research Ethics Committee (Project ID 2020-23,630-47,331).

\section{Results}

In total, 104 healthcare professionals contributed data. The sample included 48 (46\%) nurses, 33 (32\%) doctors, 19 (18\%) midwives and four (4\%) who did not provide details regarding their profession. The average age of the participants was 45.62 years $(\mathrm{SD}=11.10)$, and there were 86 females (82.7\%) and 18 males (17.3\%). Most respondents worked in metropolitan health services (67.5\%), with $20 \%$ working in regional health services and $12.5 \%$ 
in rural health services. On average, the participants had worked in their profession for 18.25 years $(\mathrm{SD}=11.90)$.

\section{Analysis \\ Confirmatory factor analysis}

A 13-factor model was specified and evaluated with the sample using confirmatory factor analysis, employing maximum likelihood estimation, in IBM AMOS 26. The model fit was evaluated using a range of goodness of fit indices. The data did not fit the 13-factor model well; upon inspections of the modification indices (M.I.s) and item content, the factors knowledge and skills did not have discriminant validity. Nevertheless, as the factors knowledge and skills are separate domains in the TDF, a final 13 factor model was retained with the rest of the factors showing adequate measures of fit (see Table 2).

\section{Discriminant validity and internal consistency reliability}

The constructs of 'subjective norm', 'self-efficacy', 'automaticity' and 'action planning' were not found to show adequate discriminant validity, as their square root of average variance extracted (AVE) were higher than the correlation between the factors [33]. Chi-square difference test was used to assess discriminant validity where the correlation between latent factors was larger than the square root of AVE. In all cases, discriminant validity was supported (see Table 3). The internal consistency reliabilities were calculated using Cronbach's alpha and values ranged from 0.60 to 0.76 .

\section{Personalised and holistic behaviours}

The mean scores for each of the constructs are presented in Table 4. The values for all the constructs indicated relatively high mean scores (above 5 on a 7 -point scale) with the exception of the 'priority' $(x=3.84)$ construct (for description, see Table 1). In this study, the cut-off means scores for each of the constructs indicating 95\% $(x \geq 6.65), 85 \%(x \geq 5.95)$ and $75 \%(x \geq 5.25)$ agreement were used. This was determined to align with the performance standards of quality care for public health services set by the Department of Health Services (DHS) in Victoria [34]. For example, public health services are expected to attain $100 \%$ on the timely access to care standard, $95 \%$ on overall patient experience of care and $75 \%$ on the coordination of care (see Table 4). The mean scores of all constructs fall below the 95\% DHS standard level. The constructs falling below 85\% are' action planning', 'automaticity', 'reinforcement,' 'social support', 'resources', 'subjective norm' and 'Skills. Only the behaviour 'priority' was below $75 \%$.

Further subgroup analyses by the professional group, role seniority, years of experience, gender and health service category variables were undertaken to examine any differences in the mean scores for each construct. No differences by gender and health service category were identified. However, significant differences were found across the professional groups $(\mathrm{p}<0.01)$, as shown in Table 5. There was no difference found in the 'social support', 'reinforcement', 'subjective norm', 'resources' and 'knowledge' behaviours. Respondents who identified as midwives reported higher mean scores in the 'self-efficacy', 'professional role', 'automaticity' and 'action planning' behaviours compared to those identified as nurses or doctors. Respondents identified as nurses reported the lowest mean scores in the 'priority' behaviours compared to the other groups.

Table 2 Confirmatory factor analysis model fit indices

\begin{tabular}{|c|c|c|c|c|c|c|c|c|}
\hline TDF Domains & Constructs & $x^{2}$ & $d f$ & CMIN/df & GFI & NFI & CFI & RMSEA \\
\hline Knowledge & Knowledge & 20.97 & 7 & 2.99 & .943 & .936 & .955 & .100 \\
\hline Skills & Skills & & & & & & & \\
\hline \multirow[t]{3}{*}{ Behavioural regulation \& Nature of behaviour } & Self-Monitoring & 9.89 & 11 & 0.90 & .975 & .969 & 1.00 & .001 \\
\hline & Action Planning & & & & & & & \\
\hline & Automaticity & & & & & & & \\
\hline \multirow[t]{3}{*}{ Environmental context and resources \& Social influences } & Resources & 26.9 & 15 & 1.79 & .946 & .922 & .962 & .080 \\
\hline & Social Support & & & & & & & \\
\hline & Subjective Norm & & & & & & & \\
\hline \multirow[t]{2}{*}{ Professional role \& Self-efficacy } & Professional Role & 7.18 & 4 & 1.79 & .971 & .949 & .976 & .080 \\
\hline & Self-efficacy & & & & & & & \\
\hline \multirow[t]{2}{*}{ Motivation \& Goals } & Action Planning & 9.34 & 8 & 1.17 & .972 & .944 & .991 & .040 \\
\hline & Priority & & & & & & & \\
\hline \multirow[t]{2}{*}{ Belief about consequences } & Outcome Expectation & 5.13 & 4 & 1.28 & .981 & .959 & .990 & .052 \\
\hline & Reinforcement & & & & & & & \\
\hline
\end{tabular}


Table 3 Correlation of factors influencing personalised and holistic care behaviours

\begin{tabular}{|c|c|c|c|c|c|c|c|c|c|c|c|c|c|}
\hline \multicolumn{14}{|c|}{ Correlation matrix of personalised care behaviours } \\
\hline Constructs & 1 & 2 & 3 & 4 & 5 & 6 & 7 & 8 & 9 & 10 & 11 & 12 & 13 \\
\hline 1. Social Support & 0.65 & & & & & & & & & & & & \\
\hline 2. Reinforce & $.40^{* *}$ & 0.66 & & & & & & & & & & & \\
\hline 3. Priority & .10 & .08 & 0.68 & & & & & & & & & & \\
\hline 4. Subjective Norm & $.66^{* *}$ & $.31^{* *}$ & .09 & 0.74 & & & & & & & & & \\
\hline 5. Self Monitoring & $.40^{* *}$ & $.28^{* *}$ & $.42^{* *}$ & $.51^{* *}$ & 0.73 & & & & & & & & \\
\hline 6. Resources & $.63^{* *}$ & $.38^{* *}$ & .17 & $.69^{* *}$ & $.54^{* *}$ & 0.57 & & & & & & & \\
\hline 7. Knowledge & $.36^{* *}$ & $.43^{* *}$ & $.31^{* *}$ & $.54^{* *}$ & $.68^{* *}$ & $.59^{* *}$ & 0.56 & & & & & & \\
\hline 8. Skills & $.45^{* *}$ & $.45^{* *}$ & $.34^{* *}$ & $.56^{* *}$ & $.62^{* *}$ & $.55^{* *}$ & $.87^{* *}$ & 0.44 & & & & & \\
\hline 9. Self-Efficacy & $.54^{* *}$ & $.55^{* *}$ & $.29^{* *}$ & $.48^{* *}$ & $.70^{* *}$ & $.58^{* *}$ & $.76^{* *}$ & $.77^{* *}$ & 0.66 & & & & \\
\hline 10 Outcome Expectation & $.38^{* *}$ & $.39^{* *}$ & $.30^{* *}$ & $.43^{* *}$ & $.41^{* *}$ & $.37^{* *}$ & $.64^{* *}$ & $.65^{* *}$ & $.59^{* *}$ & 0.78 & & & \\
\hline 11. Professional Role & $.45^{* *}$ & $.27^{* *}$ & $.26^{* *}$ & $.47^{* *}$ & $.52^{* *}$ & $.38^{* *}$ & $.59^{* *}$ & $.57^{* *}$ & $.62^{* *}$ & $.51^{* *}$ & 0.69 & & \\
\hline 12. Automaticity & $.54^{* *}$ & $.50^{* *}$ & $.36^{* *}$ & $.54^{* *}$ & $.61^{* *}$ & $.60^{* *}$ & $.81^{* *}$ & $.77^{* *}$ & $.82^{* *}$ & $.73^{* *}$ & $.64^{* *}$ & 0.72 & \\
\hline 13. Action Planning & $.65^{* *}$ & $.40^{* *}$ & $.40^{* *}$ & $.51^{* *}$ & $.67^{* *}$ & $.63^{* *}$ & $.64^{* *}$ & $.69^{* *}$ & $.71^{* *}$ & $.58^{* *}$ & $.50^{* *}$ & $.76^{* *}$ & 0.72 \\
\hline Cronbach Alpha & 0.67 & 0.68 & 0.71 & 0.69 & 0.62 & 0.60 & 0.76 & 0.68 & 0.68 & 0.73 & 0.65 & 0.69 & 0.76 \\
\hline Composite Reliability & 0.67 & 0.69 & 0.71 & 0.70 & 0.69 & 0.59 & 0.79 & 0.70 & 0.70 & 0.76 & 0.65 & 0.69 & 0.76 \\
\hline Skewness & -0.19 & -0.07 & 0.34 & -0.65 & -0.71 & -0.65 & -0.71 & -0.54 & -0.35 & -0.93 & -1.24 & -0.72 & -0.44 \\
\hline Kurtosis & -0.61 & -0.97 & -0.43 & -0.44 & -0.12 & -0.03 & 0.06 & -0.22 & -0.74 & 0.44 & 1.43 & -0.08 & -0.54 \\
\hline
\end{tabular}

Legend: ${ }^{*}=p<.05,{ }^{* *}=p<.01$ Figures in bold on the diagonal are square root of AVE, figures below the diagonal are Pearson's correlations

Table 4 Mean Score of Constructs, TDF domains and Levels of Self-reported Attainment

\begin{tabular}{|c|c|c|c|c|c|c|c|}
\hline \multirow[t]{3}{*}{ TDF Domains } & \multirow{3}{*}{$\begin{array}{l}\text { Constructs of Personalised and } \\
\text { Holistic care extracted }\end{array}$} & \multicolumn{3}{|c|}{$(n=104)$} & \multirow{2}{*}{\multicolumn{3}{|c|}{$\begin{array}{l}\text { Healthcare professionals self- } \\
\text { reported attainment levels }\end{array}$}} \\
\hline & & \multicolumn{2}{|l|}{ Mean } & \multirow[t]{2}{*}{ (S.E.) } & & & \\
\hline & & & & & $75 \%$ & $85 \%$ & $95 \%$ \\
\hline \multirow[t]{2}{*}{ Social influences } & 1. Social Support for staff & 5.67 & $(.09)$ & & & ++ & + \\
\hline & 2. Subjective Norm & 5.77 & $(.11)$ & & & ++ & + \\
\hline Motivation \& goals & 3. Priority & 3.84 & $(.12)$ & & +++ & & + \\
\hline \multirow[t]{2}{*}{ Behavioural regulation } & 4. Self-Monitoring & 6.24 & $(.07)$ & & & & + \\
\hline & 5. Action Planning & 5.43 & $(.10)$ & & & ++ & + \\
\hline Environmental context \& resource & 6. Resources & 5.67 & $(.09)$ & & & ++ & + \\
\hline Knowledge & 7. Knowledge & 6.00 & $(.08)$ & & & & + \\
\hline Skills & 8. Skills & 5.92 & $(.08)$ & & & ++ & + \\
\hline Beliefs about capabilities & 9. Self-efficacy & 6.04 & $(.07)$ & & & & + \\
\hline \multirow[t]{2}{*}{ Beliefs about consequences } & 10. Outcome Expectation & 5.98 & $(.09)$ & & & & + \\
\hline & 11. Reinforcement & 5.61 & $(.09)$ & & & ++ & + \\
\hline Professional role & 12. Professional Role & 6.04 & $(.10)$ & & & & + \\
\hline Nature of behaviour & 13. Automaticity & 5.56 & $(.11)$ & & & ++ & + \\
\hline
\end{tabular}

Legend: $+=$ below $95 \% ;++=$ below $85 \% ;+++=$ below $75 \%$

The association between role seniority and the mean scores of personalised and holistic care constructs is shown in Table 6 . Role seniority was categorised based on the job titles reported by respondents; i) Junior nurse (registered nurse, enrolled nurse), ii) Senior nurse (clinical nurse specialist, nurse unit manager, clinical educators, nurse practitioner), iii) Midwife, iv) Junior doctor (resident/intern doctor, registrar) and v) Senior doctor (consultant, senior consultant). There were insufficient data to compare group differences for junior doctors. Besides the effect of the midwife group, significant differences $(p<0.01)$ was found where senior nurses reported higher score in 'self-monitoring' than junior nurses and senior doctors. Another difference is that the junior nurse group reported lower scores in 'priority' than senior doctor and midwife groups. 
Table 5 One-way analyses of variance for the effects of professional group on personalised and holistic care constructs

\begin{tabular}{|c|c|c|c|c|c|c|c|c|c|}
\hline \multirow{4}{*}{$\begin{array}{l}\text { One-Way } \\
\text { ANOVA } \\
\text { TDF constructs }\end{array}$} & \multicolumn{9}{|c|}{ Professional Group } \\
\hline & \multicolumn{3}{|l|}{ (A) } & \multicolumn{2}{|l|}{ (B) } & \multicolumn{2}{|l|}{ (C) } & \multirow[t]{2}{*}{ F- ratio } & \multirow[t]{2}{*}{ Differences } \\
\hline & \multicolumn{3}{|c|}{ Nurse $(n=48)$} & \multicolumn{2}{|c|}{ Doctor $(n=33)$} & \multirow{2}{*}{\multicolumn{3}{|c|}{$\begin{array}{l}\text { Midwife }(n=19) \\
M\end{array}$}} & \\
\hline & M & (S.E.) & & $M$ & (S.E.) & & & & \\
\hline Social Support & 5.71 & & $(.13)$ & 5.45 & $(.15)$ & 6.02 & $(.15)$ & 2.62 & \\
\hline Reinforcement & 5.51 & & $(.12)$ & 5.48 & $(.18)$ & 5.98 & $(.21)$ & 2.07 & \\
\hline Priority & 3.39 & & (.14) & 4.07 & $(.21)$ & 4.51 & (.30) & $7.95^{* *}$ & $A<B, C$ \\
\hline $\begin{array}{l}\text { Subjective } \\
\text { Norm }\end{array}$ & 5.61 & & $(.15)$ & 5.95 & $(.17)$ & 5.87 & $(.29)$ & 1.10 & \\
\hline $\begin{array}{l}\text { Self-Moni- } \\
\text { toring }\end{array}$ & 6.10 & & $(.12)$ & 6.15 & $(.12)$ & 6.61 & $(.11)$ & $3.54^{*}$ & $C>A, B$ \\
\hline Resources & 5.60 & & $(.15)$ & 5.54 & $(.13)$ & 5.98 & $(.17)$ & 1.66 & \\
\hline Knowledge & 5.85 & & $(.12)$ & 6.01 & $(.13)$ & 6.25 & (.14) & 1.87 & \\
\hline Skills & 5.69 & & $(.12)$ & 5.95 & (.13) & 6.28 & $(.13)$ & $4.29^{*}$ & $C>A$ \\
\hline Self-efficacy & 5.99 & & $(.11)$ & 5.80 & $(.12)$ & 6.49 & $(.08)$ & $6.24^{* *}$ & $C>A, B$ \\
\hline $\begin{array}{l}\text { Outcome } \\
\text { Expectation }\end{array}$ & 5.76 & & $(.14)$ & 5.98 & $(.14)$ & 6.39 & $(.13)$ & $3.72^{*}$ & $C>A$ \\
\hline $\begin{array}{l}\text { Professional } \\
\text { Role }\end{array}$ & 5.75 & & $(.17)$ & 6.15 & $(.17)$ & 6.45 & (.13) & $3.67^{* *}$ & $C>A$ \\
\hline Automaticity & 5.33 & & $(.18)$ & 5.42 & $(.17)$ & 6.29 & $(.13)$ & $5.89^{* *}$ & $C>A, B$ \\
\hline $\begin{array}{l}\text { Action Plan- } \\
\text { ning }\end{array}$ & 5.24 & & (.16) & 5.29 & (.14) & 6.14 & $(.10)$ & $7.18^{* *}$ & $C>A, B$ \\
\hline
\end{tabular}

Legend: ${ }^{*}=p \leq .05,{ }^{* *}=p \leq .01$ Figures in bold are those constructs that are below $85 \%$ with group differences

The effect of years of experience, where respondents with less than ten years of experience reported lower scores in 'subjective norm' and 'resources' constructs than those with more years of experience is shown in Table 7.

\section{Discussion}

Overall, there was a high level of self-reported attainment and regard for personalised and holistic care behaviours among the doctors, nurses and midwives in Victoria, Australia. The results support those observed in earlier studies $[35,36]$ of healthcare professionals' acceptance of and efforts to change patient-centred practices. This study identified seven behavioural domains 'environmental context and resources', 'skills,' 'social influence,' 'beliefs about consequences', 'behavioural regulation', 'nature of behaviour' and 'motivation and goals' that are central to increased uptake of personalised and holistic care behaviours.

As found by others [37, 38], 'skills', 'environmental' (resources construct) and 'motivation and goals' (priority construct) domains are common barriers to changing healthcare professionals' behaviours in the uptake of guidelines. The findings of this study lend further support to these previous findings. The 'motivation and goals' (priority construct), where participants rate the importance of performing personalised and holistic care behaviours compared to other tasks, had the lowest score suggesting a more substantial challenge to overcome than the rest. However, it could be the result of increased workload in the public health services. This is more so given that this study was conducted during the period of strict lockdown in Victoria to combat high rates of COVID-19 infections. Beyond the conventional limitations of capability, time and resources, earlier studies [10,39] on healthcare professionals' behaviour change had begun investigating other predictors of behaviour change and drawing explanation from behavioural theories.

The study's findings of 'social influence,' 'beliefs about consequences', 'behavioural regulation' as factors that influence healthcare professionals' behaviours are significant in at least two major respects. First, to improve personalised and holistic care, there is a need to look beyond conventional challenges of capability, time and resources, as shown in earlier studies[10,39,40]. Second, there is potential for more improvement through promoting peer group norms and expectations, and reminders to adopt the desired behaviours within the context. Earlier studies found that when these factors were addressed and the behaviours became habitual, healthcare professional behaviours were changed [10, 41].

The group differences found in years of experience and role seniority indicate that when designing interventions to target the behavioural domains, there is a need to customise for those with ten or less years of experience, senior doctors and junior nurses. The reason for 


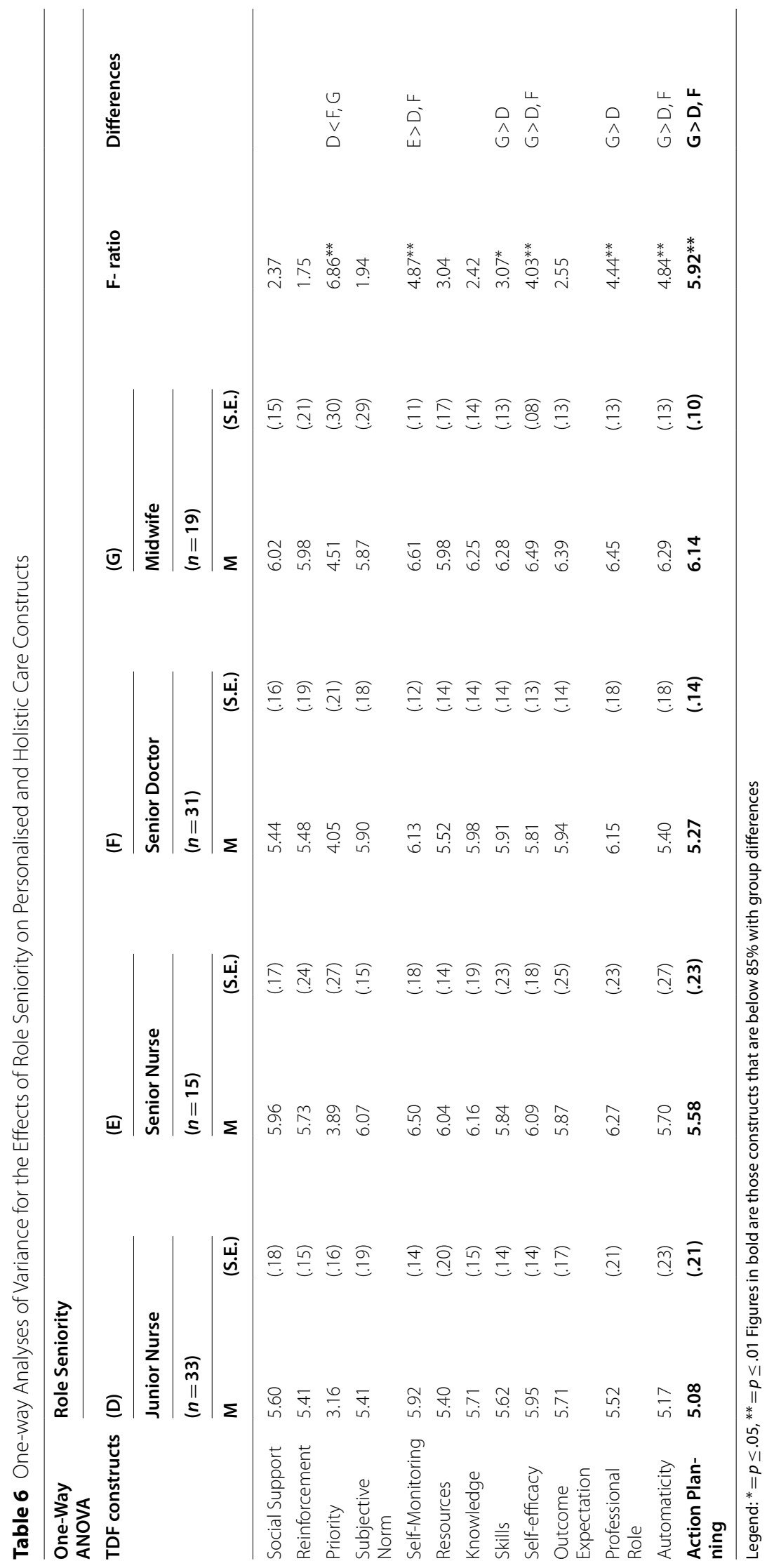


Table 7 One-way analyses of variance for the effects of years of experience on personalised and holistic care constructs

\begin{tabular}{|c|c|c|c|c|c|c|c|c|}
\hline \multirow{5}{*}{$\begin{array}{l}\text { One-Way ANOVA } \\
\text { TDF constructs }\end{array}$} & \multicolumn{8}{|c|}{ Years of Experience } \\
\hline & \multicolumn{2}{|l|}{ (H) } & \multicolumn{2}{|l|}{ (I) } & \multicolumn{2}{|l|}{$(J)$} & \multirow[t]{3}{*}{ F- ratio } & \multirow[t]{3}{*}{ Differences } \\
\hline & \multicolumn{2}{|c|}{$\leq 10$ years } & \multicolumn{2}{|c|}{$11-25$ years } & \multicolumn{2}{|c|}{$>25$ years } & & \\
\hline & \multicolumn{2}{|c|}{$(n=37)$} & \multicolumn{2}{|c|}{$(n=35)$} & \multicolumn{2}{|c|}{$(n=32)$} & & \\
\hline & $M$ & $(\mathrm{SE})$ & M & (SE) & M & $(\mathrm{SE})$ & & \\
\hline Social Support & 5.39 & $(.16)$ & 5.93 & (.13) & 5.72 & (.14) & $3.65^{*}$ & $H<I$ \\
\hline Reinforcement & 5.77 & $(.16)$ & 5.50 & $(.15)$ & 5.54 & $(.16)$ & 0.85 & \\
\hline Priority & 3.82 & $(.23)$ & 3.96 & $(.22)$ & 3.72 & $(.17)$ & 0.34 & \\
\hline Subjective Norm & 5.30 & $(.20)$ & 5.96 & (.18) & 6.11 & $(.12)$ & $6.23^{* *}$ & $\mathrm{H}<\mathrm{I}, \mathrm{J}$ \\
\hline Self-Monitoring & 6.04 & $(.14)$ & 6.30 & $(.11)$ & 6.41 & $(.12)$ & 2.39 & \\
\hline Resources & 5.20 & $(.17)$ & 5.89 & $(.11)$ & 5.97 & (.13) & $9.24^{* *}$ & $\mathrm{H}<\mathrm{I}, \mathrm{J}$ \\
\hline Knowledge & 5.86 & $(.14)$ & 5.96 & (.13) & 6.22 & $(.13)$ & 1.96 & \\
\hline Skills & 5.88 & $(.13)$ & 5.81 & $(.14)$ & 6.07 & $(.13)$ & 0.98 & \\
\hline Self-efficacy & 5.99 & $(.12)$ & 5.99 & (.13) & 6.16 & $(.12)$ & 0.58 & \\
\hline Outcome Expectation & 6.08 & $(.13)$ & 5.86 & $(.17)$ & 5.98 & $(.14)$ & 0.58 & \\
\hline Professional Role & 5.80 & $(.20)$ & 6.24 & $(.17)$ & 6.09 & $(.14)$ & 1.77 & \\
\hline Automaticity & 5.45 & $(.22)$ & 5.54 & $(.17)$ & 5.72 & $(.16)$ & 0.53 & \\
\hline Action Planning & 5.34 & (.18) & 5.40 & $(.16)$ & 5.57 & $(.14)$ & 0.50 & \\
\hline
\end{tabular}

Legend: ${ }^{*}=p \leq .05,{ }^{* *}=p \leq .01$ Figures in bold are those constructs that are below $85 \%$ with group differences

the differences is not clear or explored in this study, but it may be due to the level of autonomy and confidence in their professional practices.

\section{Strengths and limitations}

To date, this is, to our knowledge, one of the first studies to use the TDF to quantify the behavioural domains in implementing personalised and holistic care by doctors, nurses and midwives. The identified domains from the TDF can be targeted in the design of interventions to improve personalised and holistic care. This study also analysed the mean scores for the constructs by benchmarking the performance standard (95\%) required of health services instead of the usual criterion of five out of seven on a Likert scale. This resulted in the identification and prioritisation of TDF domains to focus on despite high scores overall. Personalised and holistic care is one aspect of quality of care, just like patient safety, where performance under $95 \%$ would be unacceptable and would call for urgent improvement.

Limitations of this study include the small sample size for the questionnaire and the model fit for the "knowledge' and 'skills' constructs. These could be addressed in future studies with a larger sample size and revision of the questionnaire items in these constructs. While questionnaire design met the aims of this study, it has limited the scope of the TDF, as not all domains and theoretical constructs were comprehensively covered and tested. The findings of this study are limited to the domains and related constructs tested in the questionnaire and it is unknown if the untested domains are also relevant and to what extent healthcare professionals perform these behaviours.

\section{Implications for practice}

For health service practitioners and policymakers, this study may be used to identify the influencing factors for personalised and holistic care that are not meeting the targeted standards. This allows for prioritisation of interventions. Next, there is a need to design and trial interventions tailored to the different healthcare professional groups in their context. This could be guided by theory-informed intervention functions and policy categories [17, 42-44].

\section{Implications for research and suggestions for future research}

To add to the design of theory-informed interventions for practice, a summary table (see Table 8 ) below is adapted from the authors of behaviour change wheel [45] as a start to identify intervention functions and policy categories. Future research efforts could be focused on detailed mapping and evaluation of the intervention functions and policy categories for personalised and holistic care using this framework 


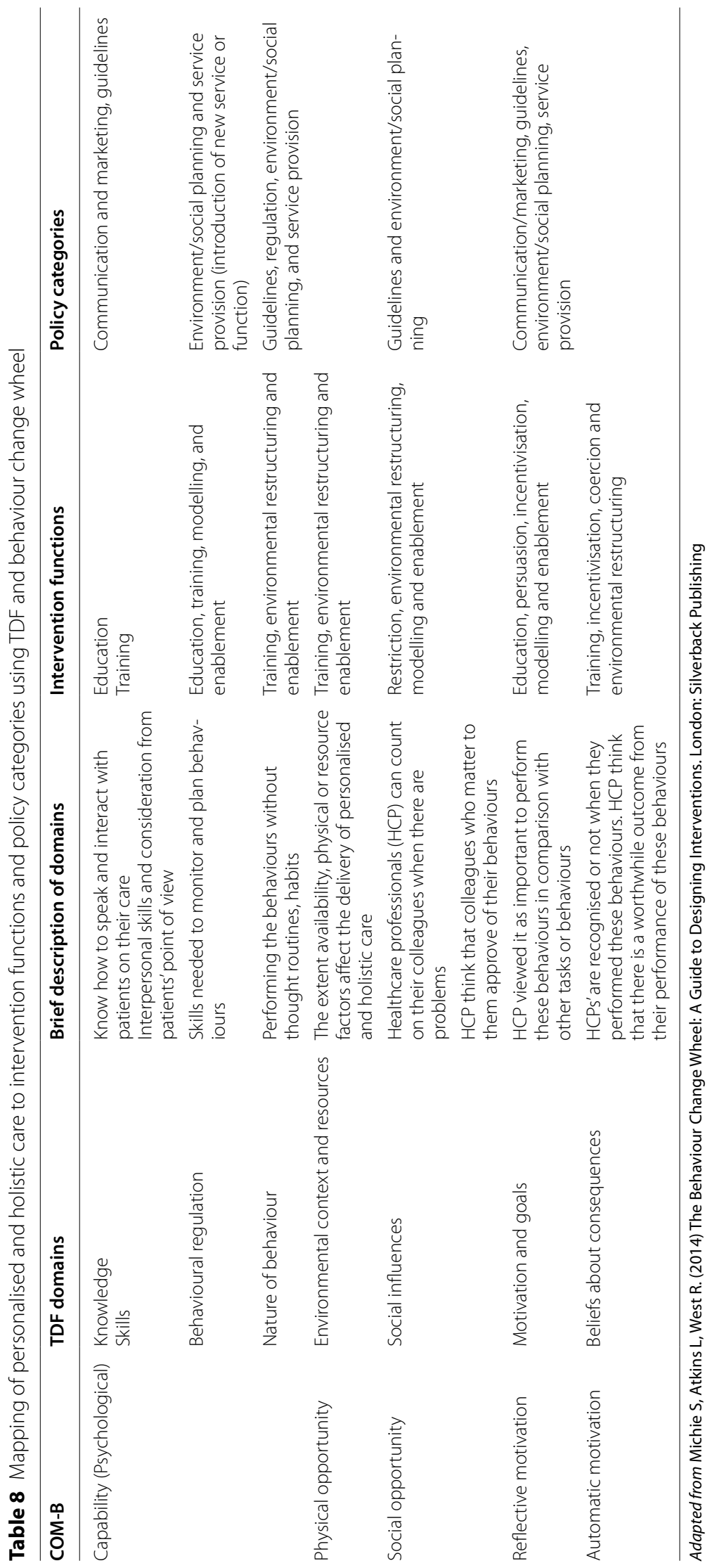


and the subsequent design of intervention strategies [46-48].

\section{Conclusion}

This study contributes to understanding factors associated with personalised and holistic care among healthcare professionals in Victoria, Australia. The self-reported performance of personalised and holistic care behaviours was relatively high but still falls short of the 95\% standard for overall patient experience set for health services. Although encouraging, further improvement is needed before personalised and holistic care is accorded the same consideration as patient safety in measuring care quality. As the way forward, future implementation and interventions can start by addressing the identified factors falling too far below the desired standards.

\section{Abbreviations}

TDF: Theoretical Domains Framework; BCW: Behaviour Change Wheel; NSQHS: National Safety and Quality Health Service; CFA: Confirmatory factor analysis; AVE: Average variance extracted; DHS: Department of Health Services.

\section{Supplementary Information}

The online version contains supplementary material available at https://doi. org/10.1186/s12913-022-07630-1.

\section{Additional file 1.}

\section{Acknowledgements}

Not applicable

\section{Authors' contributions}

EW contributed to the concept, design, data collection, data analysis, data interpretation and drafting of the manuscript. FM and JF contributed to the concept, design, data interpretation and drafting of the manuscript. LH and LM contributed to the concept, design and data collection. All authors reviewed and approved the final manuscript.

\section{Funding}

Sources of support: Eunice Wong is supported by a research higher degree scholarship jointly funded by the Australian Government Research Training Program and Safer Care Victoria. Jane Fisher is supported by the Finkel Professional Fellowship, funded by the Finkel Family Foundation. Beyond funding support, the funders had no direct role in the study design, data collection, analysis, or interpretation, or writing the manuscript.

\section{Availability of data and materials}

The datasets used and/or analysed during the current study are available from the corresponding author on reasonable request.

\section{Declarations}

Ethics approval and consent to participate

Ethics approval for this study was provided by the Monash University Human Research Ethics Committee (Project ID 2020-23630-47331). Informed consent was obtained from all subjects and/or their legal guardian(s). Study procedures conform to the 1975 Declaration of Helsinki and is subsequent revisions.
Consent for publication

Not applicable.

\section{Competing interests}

The authors declare that they have no competing interests.

\section{Author details}

${ }^{1}$ Monash Sustainable Development Institute, BehaviourWorks Australia, Monash University, Melbourne, Australia. ${ }^{2}$ School of Public Health and Preventive Medicine, Monash University, Melbourne, Australia. ${ }^{3}$ Department of Marketing, Monash University, Melbourne, Australia. ${ }^{4}$ Safer Care Victoria, Department of Health Victoria, Melbourne, Australia.

Received: 26 July 2021 Accepted: 14 February 2022

Published online: 01 March 2022

\section{References}

1. de Silva D. Helping measure person centred care: a review of evidence about commonly used approaches and tools used to help measure person-centred care. The Health Foundation. London: The Health Foundation; 2014. 76 p. Available from: http://www.health.org.uk/sites/defau It/files/HelpingMeasurePersonCentredCare.pdf

2. Doyle C, Lennox L, Bell D. A systematic review of evidence on the links between patient experience and clinical safety and effectiveness. BMJ Open. 2013;3(1):e001570. https://doi.org/10.1136/bmjopen-2012-001570 (Cited 2018 Aug 21).

3. Mead N, Bower P. Patient-centred consultations and outcomes in primary care: a review of the literature. Patient Educ Couns. 2002;48(1):51-61.

4. McMillan SS, Kendall E, Sav A, King MA, Whitty JA, Kelly F, et al. Patientcentered approaches to health care: a systematic review of randomized controlled trials. Med Care Res Rev. 2013;70(6):567-96.

5. The Australian Commission on Safety and Quality in Health Care. National Safety and Quality Health Service Standards 2nd ed. Sydney; 2017 [cited 28 Apr 2020]. Available from: http://www.safetyandquality.gov.au/wpcontent/uploads/2011/09/NSQHS-Standards-Sept-2012.pdf.

6. Horvat L. Partnering in healthcare framework. Melbourne, Australia: State Government of Victoria, Melbourne; 2019 [cited 15 Jul 2018]. Available from: https://www.bettersafercare.vic.gov.au/sites/default/files/2019-02/ Partnering in healthcare framework 2019_WEB.pdf

7. Wong E, Mavondo F, Horvat L, McKinlay L, Fisher J. Victorian healthcare experience survey 2016-2018; evaluation of interventions to improve the patient experience. BMC Health Serv Res. 2021;21(1):316. https://doi.org/ 10.1186/s12913-021-06336-0 (Cited 2021 Apr 28).

8. Davidoff F, Dixon-Woods M, Leviton L, Michie S. Demystifying theory and its use in improvement. BMJ Qual Saf. 2015;24(3):228-38.

9. Davies P, Walker AE, Grimshaw JM. A systematic review of the use of theory in the design of guideline dissemination and implementation strategies and interpretation of the results of rigorous evaluations. Implement Sci. 2010;5(1):14. https://doi.org/10.1186/1748-5908-5-14 (Cited 2020 Apr 20).

10. Johnson MJ, May CR. Promoting professional behaviour change in healthcare: what interventions work, and why? A theory-led overview of systematic reviews. BMJ Open. 2015 Sep 30 [cited 12 May 2021];5(9):e008592. Available from: http://bmjopen.bmj.com/

11. Francis JJ, Stockton C, Eccles MP, Johnston M, Cuthbertson BH, Grimshaw $J M$, et al. Evidence-based selection of theories for designing behaviour change interventions: using methods based on theoretical construct domains to understand clinicians' blood transfusion behaviour. $\mathrm{Br} J$ Health Psychol. 2009;14(4):625-46. https://doi.org/10.1348/135910708X 397025 (Cited 2020 Feb 12).

12. Safer Care Victoria SG of V. Partnering in healthcare framework | Better Safer Care. [cited 2 Mar 2021]. Available from: https://www.bettersafe rcare.vic.gov.au/publications/partnering-in-healthcare

13. Hsu C, Gray MF, Murray L, Abraham M, Nickel W, Sweeney JM, et al. Actions and processes that patients, family members, and physicians associate with patient- A nd family-centered care. BMC Fam Pract. 2019;20(1):35. https://doi.org/10.1186/s12875-019-0918-7 (Cited 2021 Apr 13). 
14. Porcheret M, Main C, Croft P, McKinley R, Hassell A, Dziedzic K. Development of a behaviour change intervention: A case study on the practical application of theory. Implement Sci. 2014;9(1):42. https://doi.org/10. 1186/1748-5908-9-42 (Cited 2020 Apr 20).

15. Horppu R, Martimo KP, MacEachen E, Lallukka T, Viikari-Juntura E. Application of the Theoretical Domains Framework and the behaviour change wheel to understand physicians' behaviors and behavior change in using temporary work modifications for return to work: a qualitative study. J Occup Rehabil. 2018;28(1):135-46. https://doi.org/10.1007/s10926-0179706-1 (Cited 2019 Feb 27).

16. Gardner B, Whittington C, McAteer J, Eccles MP, Michie S. Using theory to synthesise evidence from behaviour change interventions: the example of audit and feedback. Soc Sci Med. 2010;70(10):1618-25. https://doi.org/ 10.1016/j.socscimed.2010.01.039.

17. Atkins $L$, Francis J, Islam R, O'Connor D, Patey A, Ivers $N$, et al. A guide to using the Theoretical Domains Framework of behaviour change to investigate implementation problems. Implement Sci. 2017;12(1):1-18. https:// doi.org/10.1186/s13012-017-0605-9 (Cited 2018 Jun 14).

18. Michie S, Johnston M, Abraham C, Lawton R, Parker D, Walker A, et al. Making psychological theory useful for implementing evidence based practice: a consensus approach. Qual Saf Heal Care. 2005 Feb 1 [cited 30 Oct 2018];14(1):26-33. Available from: http://www.ncbi.nlm.nih.gov/ pubmed/15692000

19. Michie S, van Stralen MM, West R. The behaviour change wheel: A new method for characterising and designing behaviour change interventions. Implement Sci. 2011 Dec 23 [cited 15 Jul 2018];6(1):42. Available from: http://www.ncbi.nlm.nih.gov/pubmed/21513547

20. Fleming A, Bradley C, Cullinan S, Byrne S. Antibiotic prescribing in longterm care facilities: a qualitative, multidisciplinary investigation. BMJ Open. 2014;4(11):e006442.

21. Manikam L, Hoy A, Fosker H, Wong MHY, Banerjee J, Lakhanpaul M, et al. What drives junior doctors to use clinical practice guidelines? A national cross-sectional survey of foundation doctors in England \& Wales. BMC Med Educ. 2015 Dec 21 [cited 10 Apr 2019];15(1):227. Available from: http://www.biomedcentral.com/1472-6920/15/227

22. Taylor N, Parveen S, Robins V, Slater B, Lawton R. Development and initial validation of the Influences on Patient Safety Behaviours Questionnaire. Implement Sci. 2013;8(1):81 [cited 8 Mar 2019]. Available from: http:// www.implementationscience.com/content/8/1/81

23. Beenstock J, Sniehotta FF, White M, Bell R, Milne EMG, Araujo-Soares V. What helps and hinders midwives in engaging with pregnant women about stopping smoking? A cross-sectional survey of perceived implementation difficulties among midwives in the North East of England. Implement Sci. 2012;7(1):36. https://doi.org/10.1186/1748-5908-7-36 (Cited 2020 Feb 25).

24. Taylor N, Lawton R, Conner M. Development and initial validation of the determinants of physical activity questionnaire. Int J Behav Nutr Phys Act. 2013;10(1):74. https://doi.org/10.1186/1479-5868-10-74 (Cited 2019 Mar 8).

25. Huijg JM, Gebhardt WA, Dusseldorp E, Verheijden MW, van der Zouwe N, Middelkoop BJ, et al. Measuring determinants of implementation behavior: Psychometric properties of a questionnaire based on the theoretical domains framework. Implement Sci. 2014 [cited 21 Feb 2019];9(1). Available from: http://www.implementationscience.com/content/9/1/33

26. Huijg JM, Gebhardt WA, Crone MR, Dusseldorp E, Presseau J. Discriminant content validity of a Theoretical Domains Framework questionnaire for use in implementation research. Implement Sci. 2014;9(1):11. https://doi. org/10.1186/1748-5908-9-11 (Cited 2019 Feb 21).

27. Amemori M, Michie S, Korhonen T, Murtomaa H, Kinnunen TH. Assessing implementation difficulties in tobacco use prevention and cessation counselling among dental providers. 2011 [cited 18 Feb 2020]. Available from: http://www.surveymonkey.com

28. Cane J, O'Connor D, Michie S. Validation of the Theoretical Domains Framework for use in behaviour change and implementation research. Implement Sci. 2012;7(1):37. https://doi.org/10.1186/1748-5908-7-37 (Cited 2019 Mar 11).

29. Fishbein M, Ajzen I. Predicting and Changing Behavior : The Reasoned Action Approach. London, UNITED STATES: Taylor \& Francis Group; 2009. Available from: http://ebookcentral.proquest.com/lib/monash/detail. action?doc $\mid \mathrm{D}=668501$
30. van de Mortel TF. Faking it: social desirability response bias in self-report research. Aust J Adv Nurs. 2008;25(4):40-8.

31. Fisher RJ, Tellis GJ. Removing Social Desirability Bias With Indirect Questioning: Is the Cure Worse Than the Disease? Adv Consum Res. 1998 [cited 5 Dec 2020];NA-25:563-7. Available from: https://www.acrwebsite. org/volumes/8212/volumes/v25/NA-25/full

32. Taylor N, Parveen S, Robins V, Slater B, Lawton R. Development and initial validation of the Influences on Patient Safety Behaviours Questionnaire. 2013 [cited 8 Mar 2019]. Available from: http://www.implementations cience.com/content/8/1/81

33. Fornell C, Larcker DF. Evaluating structural equation models with unobservable variables and measurement error. J Mark Res. 1981;18(1):39.

34. State of Victoria Department of Health. Victorian health services performance monitoring framework 2018-2019. 2018 [cited 25 Jun 2019]. Available from: https://www2.health.vic.gov.au/hospitals-and-healthservices/funding-performance-accountability/performance-monitoring

35. Sidani S, Soeren M van, Hurlock-Chorostecki C, Reeves S, Fox M, Collins L. Health professionals' and patients' perceptions of patient-centered care: a comparison. Eur J Pers Centered Healthc. 2016 Dec 15 [cited 12 May 2021];4(4):641-9. Available from: http://www.ejpch.org/ejpch/article/ view/1177

36. Jardien-Baboo S, van Rooyen D, Ricks E, Jordan P. Perceptions of patientcentred care at public hospitals in Nelson Mandela Bay. Heal SA Gesondheid. 2016;1 (21):397-405.

37. Cabana MD, Rand CS, Powe NR, Wu AW, Wilson MH, Abboud PAC, et al. Why don't physicians follow clinical practice guidelines?: A framework for improvement. Vol. 282, Journal of the American Medical Association. JAMA; 1999 [cited 12 May 2021]. p. 1458-65. Available from: https:// pubmed.ncbi.n/m.nih.gov/10535437/

38. West E, Barron DN, Reeves R. Overcoming the barriers to patient-centred care: Time, tools and training. J Clin Nurs. 2005 Apr [cited 12 May 2021];14(4):435-43. Available from: https://pubmed.ncbi.nlm.nih.gov/ $15807750 /$

39. Bull ER, Dale H. Improving community health and social care practitioners' confidence, perceived competence and intention to use behaviour change techniques in health behaviour change conversations. Heal Soc Care Community. 2021;29(1):270-83. https://doi.org/10.1111/hsc.13090 (Cited 2021 May 12).

40. Ivers NM, Sales A, Colquhoun H, Michie S, Foy R, Francis JJ, et al. No more "business as usual" with audit and feedback interventions: towards an agenda for a reinvigorated intervention. Implement Sci. 2014;9(1):14.

41. Potthoff S, Rasul O, Sniehotta FF, Marques M, Beyer F, Thomson R, et al. The relationship between habit and healthcare professional behaviour in clinical practice: a systematic review and meta-analysis. Health Psychol Rev. 2019 Jan 2 [cited 12 May 2021];13(1):73-90. Available from: https:// www.tandfonline.com/action/journallnformation?journalCode $=$ rhpr20

42. French SD, Green SE, O'Connor DA, McKenzie JE, Francis JJ, Michie S, et al. Developing theory-informed behaviour change interventions to implement evidence into practice: a systematic approach using the Theoretical Domains Framework. Implement Sci. 2012;7(1):38. https://doi.org/10. 1186/1748-5908-7-38 (Cited 2019 Apr 10).

43. Kredo T, Cooper S, Abrams A, Muller J, Volmink J, Atkins S. Using the behavior change wheel to identify barriers to and potential solutions for primary care clinical guideline use in four provinces in South Africa. BMC Health Serv Res. 2018;18(1):965.

44. Templeton AR, Young L, Bish A, Gnich W, Cassie H, Treweek S, et al. Patient-, organization-, and system-level barriers and facilitators to preventive oral health care: a convergent mixed-methods study in primary dental care. Implement Sci. 2015 Dec 12 [cited 10 Feb 2020];11(1):5. Available from: http://www.implementationscience.com/content/11/1/5

45. Michie $S$, Atkins $L$, West $R$. The behaviour change wheel: a guide to designing interventions. London: Silverback Publishing; 2014. 1-46 p.

46. Cadogan CA, Ryan C, Francis JJ, Gormley GJ, Passmore P, Kerse N, et al. Improving appropriate polypharmacy for older people in primary care: Selecting components of an evidence-based intervention to target prescribing and dispensing. Implement Sci. 2015 Nov 16 [cited 26 Feb 2020];10(1):161. Available from: http://www.implementationscience.com/ content/10/1/161

47. Craig LE, Taylor N, Grimley R, Cadilhac DA, Mclnnes E, Phillips R, et al. Development of a theory-informed implementation intervention to improve the triage, treatment and transfer of stroke patients in 
emergency departments using the Theoretical Domains Framework (TDF): The T 3 Trial. Implement Sci. 2017;12:88 (2017). https://doi.org/10. 1186/s13012-017-0616-6.

48. Debono D, Taylor N, Lipworth W, Greenfield D, Travaglia J, Black D, et al. Applying the Theoretical Domains Framework to identify barriers and targeted interventions to enhance nurses' use of electronic medication management systems in two Australian hospitals. Implement Sci. 2017;12(1):42. https://doi.org/10.1186/s13012-017-0572-1 (Cited 2019 Apr 2).

\section{Publisher's Note}

Springer Nature remains neutral with regard to jurisdictional claims in published maps and institutional affiliations.

- fast, convenient online submission

- thorough peer review by experienced researchers in your field

- rapid publication on acceptance

- support for research data, including large and complex data types

- gold Open Access which fosters wider collaboration and increased citations

- maximum visibility for your research: over $100 \mathrm{M}$ website views per year

At BMC, research is always in progress.

Learn more biomedcentral.com/submissions 